\title{
Tackling the politics of intersectoral action for the health of people and planet
}

\author{
Kent Buse and colleagues argue that unlocking the potential for intersectoral action on climate \\ and health requires thinking politically about its facilitators and barriers
}

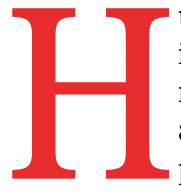

uman activities are wreaking extensive damage on the natural systems of the planet and undermining the prospects for the health of current and future populations. The 2021 report of the Intergovernmental Panel on Climate Change provided further evidence of the increasing urgency of responding to the threats posed by climate change-which the UN secretary general labelled "a code red for humanity."12

The UN climate conference in Glasgow (COP26) laid bare the highly political nature of international cooperation on climate change, and the futility of failing to recognise that the health and sustainability of the environment are the cornerstone of equitable development. ${ }^{34}$ The politics inherent in intersectoral action on climate

\section{KEY MESSAGES}

- Emphasising the co-benefits to health of actions to counter environmental change in other sectors could help to motivate more ambitious intersectoral action

- Intersectoral action is beset by political challenges, as evidenced by the watered down commitments that emerged from the COP26 summit in Glasgow

- Barriers to intersectoral action include outdated institutions, the influence of vested interests, and limited ability of evidence and technocratic approaches to shift the political dial

- Enablers include political demands arising from social movements that are pressuring governments to confront climate breakdown and its impacts on human health

- The key to unlocking the potential for intersectoral action will be visionary leaders defining ambitious, long term shared goals that motivate civil society action, and independent monitoring and health may be less visible than COP26 but must be addressed to deliver the goals of the Paris agreement (box 1$)^{7}$

International health manifestos have long called for intersectoral action, ${ }^{89}$ and it is a central tenet of the UN's sustainable development goals. Nonetheless, progress on climate-health intersectoral action has been meagre despite recognition of their shared determinants. ${ }^{10-12}$

The scale and magnitude of the challenges facing humanity in the Anthropocene epoch provide a new imperative for intersectoral action on climate and health. The literature offers many lessons on the mechanisms and conditions under which intersectoral action is effective, often describing its barriers and facilitators. We argue that the key to making climate-health intersectoral action work, hinges on thinking politically about it (box 2).

Barriers and facilitators to intersectoral action Health (and illness) results from actions taken by individuals, communities, corporations, and governments within and, crucially, outside the health sector. The same logic applies to planetary health ${ }^{16}$ with health, business, and environment literature reporting similar barriers to, and facilitators of, intersectoral action. ${ }^{17-22}$ We conducted a pragmatic review, grouping the wide variety of barriers and opportunities described into seven themes (box 3). Table 1 gives a purposefully selected set of case studies, showing these facilitators and barriers at different levels in diverse geographical settings.

\section{Applying a political lens to barriers Lack of political support}

The lack of political support to impose shared cross sectoral goals across fragmented bureaucratic structures is a substantial constraint to intersectoral action. A signal that those in authority value such action is needed to establish the policies, financing, and structures to facilitate and incentivise collaboration; put the right people in boundary spanning posts; and to ensure accountability mechanisms to drive, chart, and correct progress.

The long timeframes and complexity involved can dissuade leaders from spending political capital on intersectoral action. When intersectoral action would entail confrontation with commercial interests, power imbalances between private and public sectors can lead to political apathy. And even if there are attempts to address these imbalances to overcome such apathy (as in the case of Thailand's National Health Commission

Box 1: Climate emergency imperative for intersectoral action ${ }^{56}$

- Both adaptation and mitigation are required to reduce the health effects of climate change, but to be effective they must be transformational, targeting the political and economic systems that maintain the status quo

- Adaptation aims to manage the risks posed by environmental changes. Mitigation aims to cut greenhouse gas emissions that are causing climate change. Increasingly adaptation and mitigation need to be integrated to minimise trade-offs and support equitable solutions. Both require actions across multiple sectors, including energy, housing, industry, transport, waste, water and sanitation, health, and agriculture, food, and land use

- Many of the actions also have benefits for health-for example, by reducing air pollution from burning fossil fuels, promoting physical activity through increases in active transport, and supporting healthy, low environmental impact dietary choices

- Well designed and implemented carbon pricing and subsidy removal can accelerate intersectoral action by redirecting resources to actions that improve health equity as well as cutting greenhouse gas emissions

- Health indicators should be integrated into reporting of efforts to reduce emissions and build resilience to climate change as well as fostering planetary health more widely 


\section{Box 2: Thinking politically about intersectoral action-the "three l's"}

In considering intersectoral action it is important to ascertain the underlying distribution and exercise of power by those involved. Hence, the extent to which intersectoral action facilitators can be realised and barriers overcome depends on the associated political dynamics (who gets what, when, and how ${ }^{13}$ ). This is reflected in the policies and policy environments associated with intersectoral action, and these are influenced by the three l's ${ }^{1415}$ :

- Ideologies-ideas, values. and beliefs that influence political positions and the framing employed to inspire action

- Interests-incentives facing stakeholders to engage on specific issues and the power they wield as well as the commitment with which those interests are pursued

- Institutions-structural factors that shape the rules governing policy processes

and Assembly, which attempted to do so by involving all key stakeholders, table 1), policy makers will often remain cautious in tackling vested commercial interests. Despite the centrality of politics to the success of intersectoral action, a review of the governance supporting a health in all policies approach found "significant naiveté when it comes to the politics and power games and the role that the health sector can or should play." 38 The same is true in the environment sector. For example, an analysis of intersectoral action to stop deforestation concludes that it takes civil society activism to apply pressure on decision makers to take the lead on intersectoral action. ${ }^{39}$

\section{Inadequate leadership and links across sectors}

A core leadership function of government is to promote the public good and mitigate public harm, particularly through regulatory and fiscal measures. With the imbalance of economic power between government and industry (corporations rather than states now comprise most of the world's 100 largest revenue generators), ${ }^{40}$ leadership for effective regulation to address critical public issues across multiple sectors is increasingly challenging and inadequate.

\begin{tabular}{l} 
Box 3: Barriers and facilitators of \\
intersectoral action \\
\hline Barriers \\
- Lack of political support \\
- Inadequate leadership and links across \\
sectors \\
- Organisational and institutional \\
constraints \\
Facilitators \\
- Executive leadership \\
- Shared cross sectoral goals and \\
coordination \\
- Civic mobilisation \\
- Accountability
\end{tabular}

Lack of leadership on the intersectoral action agenda reflects competing interests and ideologies and weak links across these. Scientific evidence on topics from tobacco to climate change has been undermined by vested interests sowing doubt to weaken the case for action. ${ }^{41}$ In the health sector, perhaps the most important barrier is that many people in leadership positions have a biomedical focus and either do not appreciate the critical role of the political and social determinants of health or are overwhelmed by unfamiliar challenges. ${ }^{42}$ For some, leadership on intersectoral action would mean establishing new relationships outside their comfort zones. Others may view intersectoral action as a threat to their authority or resources-affecting their interests and hence incentives for collaboration. The City Blueprint Approach to improve water management in Ahmedabad, India, reflects reluctance to meaningfully engage dissenting or critical voices, with a review noting that when solutions are needed quickly, "governmental agencies perceive stakeholder consultation a bit like an obstacle that slows down the city's rapid development" (table 1). ${ }^{35}$

\section{Organisational and institutional constraints}

These barriers to intersectoral action stem partly from organisational cultures and disciplinary training. Narrow specialisation may not value collaboration and cooperation nor foster mindsets and skillsets amenable to working with other sectors, as well as encouraging inaccessible, specialist language. These weaknesses might result in a failure to consider incentives and goals pursued by other sectors, which is essential for sustainable collaboration. In the case of cooperation on health in all policies, it has been argued that "starting with the health argument may be counterproductive or politically inappropriate." 38 There is also institutional inertia that hinders organisations established with a limited set of goals from pivoting to embrace shared goals. So, while organisational cultures remain more likely to lead to rivalry than a spirit of cooperation for intersectoral action, leaders who have collaborative tendencies may find themselves on the periphery of policy making. ${ }^{38}$

\section{Applying a political lens to facilitators Executive leadership}

Executive leadership (that is, leadership that transcends ministries, sectors, or departments), exercised at all levels, is a critical facilitator. Such leadership creates the ultimate political will for sectors to cooperate in that it is authoritative, can shape mandates, and demand compliance. The exercise of that leadership can take many forms, including altering the incentive structures of those who might otherwise pursue narrow sectoral goals; appointing boundary spanning staff (with contacts in and understanding of the culture of both organisations) to positions of authority; and establishing institutional arrangements and environments across government that facilitate intersectoral action.

Executive leadership is uniquely placed to provide intersectoral action on finance and cross sector budgets, as well as the mechanisms to hold ministries and other organisations accountable. By virtue of their positions, executives can often see the bigger picture, including overarching goals that transcend sectors, and define narratives that speak to shared values and inspire those around them to action.

What creates and sustains such leadership varies according to context; it might be a response to international commitments, a new economic imperative, carefully crafted narratives from advocates, or political demands from specific constituencies.

\section{Shared cross sectoral goals and coordination}

Structural mechanisms established by governments for coordination across ministries through joint committees, shared workplans, and pooled budgets are crucial to intersectoral action, as exemplified in the health in all policy approaches. From a political perspective, the success of these initiatives depends on acknowledging and accommodating diverse and sometimes competing interests. "Soft" elements are also important, including the creation of organisational cultures and ideologies that reward such efforts, providing incentives, and building informal networks across ministries to foster shared values 


\section{Table 1 | Examples of intersectoral action programmes and how they are facilitated* \\ Example Description Facilitation}

Global

Global action plan for healthy The GAP initiative brings together 13 multilateral

lives and well being for all health, development, and humanitarian agencies to better support countries to accelerate progress towards the health related sustainable development goals (SDGs). GAP serves as a platform for intersectoral action by better aligning their ways of working to reduce inefficiencies and provide more streamlined support to countries

The United Nations Joint Program on AIDS (UNAIDS) ${ }^{24}$
A joint programme of $11 \mathrm{UN}$ agencies with a mandate to lead the global AIDS response. Each agency has specific mandates ranging from gender equality to decent work to education, all of which are relevant to a robust AIDS response. UNAIDS was established to provide intersectoral action across the various determinants of HIV, and provides an example of civil representatives mobilising to achieve intersectoral action

- The mandate for the GAP initiative came from three heads of state with the backing of the UN secretary general

- It involves multilateral health, development, and humanitarian member organisations (such as WHO, GAVI, World Bank) working to support countries to accelerate progress against SDG 3 targets

- Executive heads of member organisations constitute the principals of the GAP and are accountable for its success: they set strategic direction, evaluate progress, and report annually, providing leadership and support from the top

- Day-to-day functioning is vested in focal points-staff appointed by the heads of agency. They develop, discuss, and agree the overall GAP workplan, the monitoring framework, and monitor progress. Importantly, they coordinate relevant actions within their own agencies to further the joint plan

- The intersectoral work is undertaken in thematic working groups-eg, on financing, research, determinants, and meaningful engagement of civil society. Teams of GAP members support countries with the various offerings of the working groups to help countries implement programmes addressing the health related SDG targets. The GAP is supported by a small secretariat to provide glue to the initiative

- Accountability is ensured by regular reports as well as a planned independent external evaluation

- UNAIDS structure involves a board made up of representatives from UN agencies, governments, and affected civil society organisations.

- Executive leadership is exercised by representation of chair at ministerial or ambassadorial level and among the co-sponsors by heads of agency

- A formal division of labour among UN agencies, a pooled budget, shared accountability framework, and dedicated secretariat all facilitate intersectoral action. A the technical level, formal and informal working groups facilitate collaboration across agencies

- The board meets twice a year to report on progress towards shared goals, providing accountability

- One barrier to negotiate is the fact each of the UN agencies has its own mandate. This inevitably means the level of engagement and support of activities in the shared plan depends on the extent to which their boards demand it of them

Research showing the damage to ozone layer from chloroflurocarbons provided the

Montreal Protocol on

Substances that Deplete the Ozone Layer
A global agreement to protect the Earth's ozone layer by phasing out the chemicals that deplete it. It is an example of science mobilising intersectoral action efforts

\section{basis for action ${ }^{25-27}$}

- In 1985 the Vienna Convention for the Protection of the Ozone Layer was created ${ }^{28}$

- The Montreal protocol followed two years later, establishing a shared action plan and accountability framework; it provides a set of practical, actionable tasks agreed to in 1987 and achieved universal participation with confirmation by every country on 16 September $2009,^{29}$

- The parties to the protocol meet annually to make decisions, including adjustments or amendments aimed at ensuring the successful implementation of the agreement. One such meeting led to the Kigali amendment in 2016 to cut production and consumption of hydrofluorocarbo ${ }^{\text {n3 }} \mathrm{O}$

Country
Thailand's National Health
Act $^{31}$

Thailand implemented a National Health Act in 2007. The act "secured participation as the basic orienting principle and practice in health policy making in Thailand"

- The National Health Act established the National Health Commission (NHC) chaired by the prime minister and made up in equal parts of the "triangle that moves the mountain": the knowledge sector (technical knowledge, health professionals), the government sector (politicians, local services), and the people sector (civil society, media, private sector). Importantly, 50\% of the membership must come from outside the healthcare sector

- The National Health Commission convenes an annual national health assembly which brings the three sides of the triangle together to discuss health policy and reports to the Cabinet.

- The annual assembly process addresses power imbalances through equal representation of each sector, with equal speaking rights; varying points of view are welcomed, and every attempt is made to put all sides on an equal footing (through capacity building, awareness raising work, etc). If a consensus cannot be reached on a particular point, the agenda item will be deferred to allow for more consultation time.

- Involving all key actors in the national health assembly process provides accountability and shared learning

- Provides grant funding to not-for-profit organisations to launch campaigns that engage, organise, and mobilise advocates to improve the food and physical activity policy changes to improve food and physical activity environments to promote healthy weight for environment at state or local levels

all children and adolescents in the United States" • The multisectoral collaboration model adopted enabled over 140 stakeholder organisations to align resources

- Robust accountability mechanisms with third party evaluations were established to collect, evaluate, and provide feedback to ensure continual improvement

- Executive leadership, strong political will, and financial resources (donor support or clear economic incentives) facilitated implementation at scale

- There is shared leadership for development of joint cross sectoral goals, workplans, and coordination arrangements (through data on rabies prevention and control, avian flu, and flood risk management) 


\begin{tabular}{ll}
\hline $\begin{array}{l}\text { Table } 1 \text { | Continued } \\
\text { Example }\end{array}$ & Description \\
\hline $\begin{array}{l}\text { Local or municipal } \\
\text { in local municipalities, } \\
\text { Sweden }\end{array}$ & $\begin{array}{l}\text { Nature based approaches recognise that human } \\
\text { societies and their development are dependent } \\
\text { on natural systems. These approaches were } \\
\text { implemented into the daily planning practices and } \\
\text { associated governance of Swedish municipalities }\end{array}$ \\
\hline
\end{tabular}

Facilitation

- Municipal staff and individual champions overcame multiple constraints (institutional and organisational; policy and legal; financial and human resources; knowledge and capacity) by employing targeted stakeholder collaboration, strategic citizen involvement, alteration of internal cooperation structures, outsourcing, and concealed integration of science and policy

- Civic support was mobilised at the planning phase through diverse activities aimed at increasing public awareness and avoiding protest, such as planning walks, planning games, digital dialogues, and targeted media

- Robust accountability mechanisms included changes to internal cooperation, working structures, and capacities to ensure integration; shifting from working in silos towards more intersectoral work; and improving communication by breaking down formalities

- Concealed science-policy integration progressively mainstreams scientific considerations into informal and formal planning regulations and tools through incremental, and thus little noticed, changes

City Blueprint Approach in The City Blueprint Approach provides a framework Ahmedabad, India ${ }^{35}$ for governance, sharing knowledge and facilitating integration between the scientific and policy communities working on urban water management

- An assessment of Ahmedabad's water governance using the City Blueprint Approach identified areas for improvement, which would in turn improve the city's ability to address water challenges

- Executive leadership was evidenced by visionary agents within the government who used their authority to set ambitious goals for all five water related challenges However, insufficient statutory compliance and the inadequate use of policy instruments limited the attainment of these goals, while monitoring and policy evaluation were insufficient to improve implementation

- Connecting science and policy was seen as key to resolving water governance challenges, including reliable information, stakeholder engagement, and implementing capacity

- The study showed that capacity to address one of the five challenges (urban heat islands) was high. A plan included steps that would address identified water governance issues overall (ie, learning, stakeholder engagement, and implementing capacity). This set an example of how Ahmedabad may be able to address the other four challenges

Inherit; promoting healthier, Inherit is a project funded under the EU Horizon sustainable lifestyles in EU cities $^{36}$ 2020 research programme that aims to identify, investigate, and promote effective intersectoral

- Shared goals and cooperation agreements were notable; participating partners saw the necessity and mutual benefits of both

- Other facilitating factors included being acknowledged by the outside world and policies, interventions, and innovations that enable by important stakeholders as well as having an open attitude and long term vision, and encourage healthier, more sustainable, and equitable behaviours and lifestyles

flexibility, and people feeling they could trust and rely on one another

- Participants saw the motivation and competence of partners as vital facilitators of cooperation and they seemed intrinsically motivated to make the initiative successful

- Executive leadership as well as shared, cross-sectoral goals and coordination are A greener and smarter city, Korea, Seoul ${ }^{37}$ Seoul metropolitan government (SMG) declared a sustainable policy initiative along with action plans for environmental management, creative economic development, and improvement of social equity, focused on creating decent jobs for residents through public-private partnerships

ecol in the collaboration of SMG with communities and local industry on every urban regeneration project in Seoul, to sustain economic activities and promote new opportunities. Project success is measured by economic development as well as physical improvement

- The administration established an information disclosure policy division aimed at disclosing administrative information and creating new economic and social values through information sharing

- Under the residents' participation budget system residents are able to decide how around $\$ 45 \mathrm{~m}$ should be used each year

- Policy workshops are held frequently to gather the opinions of experts and residents on SMG policies, and to reflect those views in future policies to maintain the cities competitive edge and residents' quality of life

*Studies identified by using Google Scholar to search for articles published between 2011 and 2021 using the search terms "political” OR "politics" OR “environment” OR "environmental"+"cross sector" OR "multi sector" OR "intersectoral" and selecting those that indicated an examination of political factors in intersectoral action of either health or environmental spaces. Additional cases were identified through a Delphi process based on the authors' expertise and experience.

and trust. They tend to rely on a leadership style, interpersonal behaviour traits, and skill sets such as persuasion, nudging, negotiation, conflict resolution, and trust building.

\section{Civic mobilisation}

Changing behaviour for human and planetary health requires interaction between the public (both as citizens and consumers), policy makers, and private sector leaders. Governments have an obligation to serve public interests, including protection against commercial interests, but this often requires "bottom-up" demand.
The Montreal protocol on ozone depleting compounds provides a good example of the science community providing compelling evidence around which to mobilise and foster commitment to change (table 1$).{ }^{4344} \mathrm{Citi}$ zens have an important role in demanding change or more ambitious action ${ }^{45}$ through consumer choices, civil society organisations, and social movements (for example, driving the introduction of nature based planning in Sweden, table 1). They can also be a powerful voice demanding urgent and coordinated action across government, as shown by the activism of the AIDS movement (table 1).

\section{Accountability}

Robust governance and accountability mechanisms are a prerequisite for intersectoral action as they document responsibility for actions. Legislation in support of intersectoral action, often in response to political mobilisation, can have a similar effect as it draws on established mechanisms in government to ensure accountability, and moreover can have a lasting effect beyond any particular administration. Examples include the Public Health Act in South Australia and the mandate for health equity in Scandinavian municipality budgets. ${ }^{4647}$ 
Poorly conceived intersectoral action can lead to blurred lines of accountability. This can be mitigated with clear goals, an explicit division of labour, and integrated accountability wherein the contributions of different sectors are considered holistically. Independent review by people who are not directly involved in policy or implementation can identify barriers such as vested interests as well as shared goals and lessons. The UN secretary general's independent accountability panel for the Every Woman Every Child project shows the success of this approach (box 4). Community groups with lived experience or advocacy groups can also provide accountability by applying pressure to ensure intersectoral action.

\section{Going forward}

The facilitators of intersectoral action seem to be synergistic. From a political perspective, leadership on intersectoral action would be more forthcoming if there were demands from civil society, as exemplified by the Montreal protocol. And sectoral leadership would be more responsive to intersectoral action if inspired by the vision of what it can deliver, transcending the insular mantras and priorities of any individual sector.

Compelling narratives are also key to mobilising politicians and the public. The independent accountability panel suggests that putting people, as opposed to economic growth, at the centre of policy can help secure support. Those vested in human health and planetary health share the fundamental value of tackling inequality, which ought to provide common ground to foster collaboration.

From the top, a more systematic approach with clearer articulation of which ministries should initiate and lead on different intersectoral action on climate and health issues is critical, not least so that the relevant people can be held accountable, including by civil society. Nonetheless, if intersectoral action is to be effective in different contexts, global concepts such as net zero and forest loss need to be translated to local situations with context specific solutions. And for sustained climate-health intersectoral action it will be critical that the current demands are channelled into legislation. Litigation can help to advance mitigation action, and about 1000 cases have been brought worldwide between 2015 and 2021. ${ }^{49}$

Well designed and implemented carbon pricing and subsidy removal can accelerate intersectoral action by redirecting resources to actions that improve health equity as well as cutting greenhouse gas emissions. ${ }^{50}$ Health indicators should be integrated into reporting of efforts to reduce emissions and build resilience to climate change as well as fostering planetary health more widely.

To date, political dynamics have served as barriers to intersectoral action. Yet there are grounds for optimism. The Human Rights Council recently recognised the right to a healthy environment, ${ }^{51}$ which may lead to greater attention, new legislation, and litigation on climate-health intersectoral action. The activism of climate campaigners provides further reasons for hope. It may newly politicise public health, which has grown away from its overtly political roots, ${ }^{52}$ and thus encourage intersectoral action. It may also confront the shared commercial determinants of illness and environmental degradation by demanding more effective regulation. At the same time, public health should aim to diminish political polarisation by focusing on common aspirations for a healthy and

Box 4: UN independent accountability panel: a model for intersectoral action

- The UN secretary general mandated the formation of the independent accountability panel for the Every Woman, Every Child, Every Adolescent (EWEC) initiative in $2016^{48}$

- The group of experts evaluated 10 years of work in the EWEC movement and evolved its accountability framework. In the process, they consulted widely, gathered, and evaluated evidence and listened to people's experiences of accountability for their health and rights

- In the resulting report the panel sets out an accountability framework for health across the sustainable development goals (SDGs)

- The overarching recommendation is to move towards holistic, people centred accountability by meaningfully engaging all major SDG groups and other stakeholders at regional, country and global levels, and institutionalising an independent review mechanism for intersectoral action on health across the SDGs

- The framework provides a coherent, evidence based tool that any country or organisation can use to inform its accountability

sustainable future that can command widespread support.

Divisions are emerging within the private sector between those that see their future business model tied to a more sustainable economy and those who base their future on opposing change, with a large middle group that could lean in either direction depending on consumer demand and regulatory pressures. The challenge is to strengthen those focused on a more sustainable economy and influence the undecided by calling out attempts at "greenwashing." Accountability for progress on climate-health intersectoral action ought ultimately to be to the electorate, not shareholders, although shareholders could have a positive role. Substantial investment is required in informing and engaging the public on tracking commitments made by governments and corporations, as well as in independent verification.

Linking climate-health intersectoral action to existing political processes holds considerable promise. One opportunity lies in the development of the UN Framework Convention on Climate Change, building on work on health in the nationally determined contributions to climate action under the Paris agreement. ${ }^{53}$ Another opportunity lies in the review process of the sustainable development goals, which spans from local up to a high level political forum. ${ }^{54}$ Building on the lessons from the UN secretary general's independent accountability panel, establishing an independent review mechanism to report on climate-health intersectoral action to the forum could provide the structure to drive progress.

The climate emergency provides renewed impetus to motivate political leaders to capitalise on the opportunities for climatehealth intersectoral action. The sooner we act politically on the facilitators and barriers to intersectoral action, the closer humanity will be to realising the right to a healthy environment and the goals of sustainable development.

Contributors and sources: This article builds on a webinar chaired by GT and hosted by the George Institute for Global Health in May 2021 on the intersectoral action needed for the future health of people and planet, at which $\mathrm{AH}$ gave the keynote speech. SK, JM, and OPO contributed insights and case studies to the panel discussion from multilateral, country, and health systems experiences, respectively. $\mathrm{KB}$ led the framing and drafting of the article. In addition to project management, AA and MvdM's experience in communications and engagement further strengthened the messaging.

Competing interests: We have read and understood $\mathrm{BMJ}$ policy on declaration of interests and declare the 
following: KB has received grants or contracts from WHO and the Bill and Melinda Gates Foundation; SK was co-chair of the BMJ 2018 series on making multisectoral collaboration work; $\mathrm{AH}$ is principal investigator of the Pathfinder Initiative funded by Wellcome (grant number 221284/Z/20/Z) with support from the Oak Foundation (grant number OFIL-20-093). He is co-investigator on the Complex Urban Systems for Sustainability and Health (CUSSH) project, which is supported by Wellcome [209387] Trust and on the Sustainable Healthy Food Systems project supported by the Wellcome Trust [205200]. He also received part time salary support to his institution as Wellcome Trust adviser on climate change and health (March-October 2021)

Provenance and peer review: Commissioned; externally peer reviewed.

This article is part of a series commissioned for the Prince Mahidol Awards Conference (PMAC) in January 2022. Funding for the articles, including open access fees, was provided by PMAC. The $B M /$ commissioned, peer reviewed, edited, and made the decision to publish these articles. Rachael Hinton and Kamran Abbasi were the lead editors for The BMJ.

Kent Buse, professor ${ }^{1}$

Göran Tomson, professor ${ }^{2,3}$

Shyama Kuruvilla, senior strategic adviser ${ }^{4}$

Jemilah Mahmood, executive director ${ }^{5}$

Anastasia Alden, communications manager ${ }^{1}$

Maarinke van der Meulen, programme manager ${ }^{6}$

Ole Petter Ottersen, professor ${ }^{2}$

Andy Haines, professor ${ }^{7}$

${ }^{1}$ George Institute for Global Health, Imperial College London, London, UK

2Karolinska Institutet, Stockholm, Sweden

${ }^{3}$ Swedish Institute for Global Health Transformation, Royal Swedish Academy of Sciences, Stockholm, Sweden ${ }^{4}$ World Health Organization, Geneva, Switzerland ${ }^{5}$ Sunway Centre for Planetary Health, Sunway University, Malaysia

${ }^{6}$ George Institute for Global Health, Sydney, Australia ${ }^{7}$ London School of Hygiene and Tropical Medicine, London, UK

Correspondence to: KBuse

KBuse@georgeinstitute.org

\section{(c) $\underset{\mathrm{Bv}}{(1)}$ Ne OPEN ACCESS}

This is an Open Access article distributed in accordance with the Creative Commons Attribution Non Commercial (CC BY-NC 4.0) license, which permits others to distribute, remix, adapt, build upon this work non-commercially, and license their derivative works on different terms, provided the original work is properly cited and the use is non-commercial. See: http://creativecommons.org/licenses/by-nc/4.0/.

\section{Check for updates}

1 IPCC. Climate change 2021: the physical science basis. Contribution of working group I to the sixth assessment report of the Intergovernmental Panel on Climate Change. Cambridge University Press. 2021.

2 United Nations. Secretary-general's statement on the IPCC Working Group 1 report on the physical science basis of the sixth assessment. 2021. www.un.org/ sg/en/content/secretary-generals-statement-theipcc-working-group-1-report-the-physical-sciencebasis-of-the-sixth-assessment

3 United Nations. Climate change. Planetary health. https://unfccc.int/climate-action/un-global-climateaction-awards/planetary-health
4 United Nations. Sustainable development goals: 17 goals to transform our world. www.un.org/ sustainabledevelopment/sustainable-developmentgoals

5 Crane M, Lloyd S, Haines A, et al. Transforming cities for sustainability: a health perspective. Environ Int 2021;147:106366. . doi:10.1016/j. envint.2020.106366

6 Haines A, McMichael AJ, Smith KR, et al. Public health benefits of strategies to reduce greenhouse-gas emissions: overview and implications for policy makers. Lancet 2009;374:2104-14 . doi:10.1016/ S0140-6736(09)61759-1

7 Whitmee S, Haines A, Beyrer C, et al. Safeguarding human health in the Anthropocene epoch: report of The Rockefeller Foundation-Lancet Commission on planetary health. Lancet 2015;386:1973-2028. doi:10.1016/S0140-6736(15)60901-1

8 World Health Organization. Declaration of Alma-Ata: international conference on primary health care, Alma-Ata, USSR, 6-12 September 1978. www.who. int/publications/almaata_declaration_en.pdf

9 World Health Organization. Ottawa charter for health promotion, 1986. www.who.int/publications/i/item/ ottawa-charter-for-health-promotion

10 Tomson G, Causevic S, Ottersen OP, et al. Solidarity and universal preparedness for health after covid-19. BMJ 2021:372:n59. doi:10.1136/bmi.n59.

11 Haines A, Ebi K. The imperative for climate action to protect health. N Engl / Med 2019;380:263-73. doi:10.1056/NEJMra1807873

12 Friel S, Bowen K, Campbell-Lendrum D, Frumkin H, McMichael AJ, Rasanathan K. Climate change, noncommunicable diseases, and development: the relationships and common policy opportunities. Annu Rev Public Health 2011;32:133-47. . doi:10.1146/annurevpublhealth-071910-140612

13 Lasswell DH. The political writings of Harold D Lasswell: psychopathology and politics; politics who gets what, when how; democratic character. Free Press, 1951: 525

14 John P. Analyzing public policy. 2nd ed. Routledge, 2012.

15 Weiss $\mathrm{CH}$. Ideology, interests, and information. In: Callahan D, Jennings B, eds. Ethics, the social sciences, and policy analysis. The Hastings Center series in ethics. Springer, 1983. doi:10.1007/9781-4684-7015-4_9

16 Ssennyonjo A, Van Belle S, Titeca K, Criel B, Ssengooba F. Multisectoral action for health in low-income and middle-income settings: how can insights from social science theories inform intragovernmental coordination efforts? BMJ Glob Health 2021;6:e004064. doi:10.1136/ bmigh-2020-004064

17 Mondal S, Van Belle S, Maioni A. Learning from intersectoral action beyond health: a meta-narrative review. Health Policy Plan 2021;36:552-71. doi:10.1093/heapol/czaa163

18 Kriegner S, Ottersen T, Røttingen JA, Gopinathan U. Promoting intersectoral collaboration through the evaluations of public health interventions: insights from key informants in 6 European countries. Int J Health Policy Manag 2021:10:67-76.

19 Kuruvilla S, Hinton R, Boerma T, et al, PMNCH Multisectoral Collaboration Study Group. Business not as usual: how multisectoral collaboration can promote transformative change for health and sustainable development. BMJ 2018;363:k4771. doi:10.1136/bmj.k4771

20 Rasanathan K, Bennett S, Atkins V, et al. Governing multisectoral action for health in low- and middleincome countries. PLoS Med 2017:14:e1002285. doi:10.1371/journal.pmed.1002285

21 Fitz C, Gerald MS. LSE blog, 9 Mar 2020. https:// blogs.Ise.ac.uk/socialpolicy/2020/03/09/why-cantwe-all-just-get-along-barriers-to-collaboration-andearly-thoughts-on-how-to-overcome-them-in-publicservices/
22 Verreynne M, Torres de Oliveira R, Mention AL. Enablers and barriers to industry-research collaboration: A small and medium sized enterprise perspective. CSIRO, 2021

23 World Health Organisation. Global action plan for health lives and well being for all: overview of GAP operating model. 2020. https://www. who.int/docs/default-source/global-action-plan/ operating-model-graph-and-narrative-web-version. pdf?sfvrsn=2c02de89_4

24 UNAIDS. Global review panel on the future of the UNAIDS joint programme. Refining and reinforcing the UNAIDS joint programme model. www.unaids. org/sites/default/files/media_asset/final-report_ grp_en.pdf

25 Molina M, Rowland F. Stratospheric sink for chlorofluoromethanes: chlorine atom-catalysed destruction of ozone. Nature 1974:249:810-2. doi:10.1038/249810a0

26 American Chemical Society. Chlorofluorocarbons and ozone depletion: a national historical chemical landmark. www.acs.org/content/acs/en/education/ whatischemistry/landmarks/cfcs-ozone.html

27 Farman J, Gardiner B, Shanklin J. Large losses of total ozone in Antarctica reveal seasonal $\mathrm{ClO}_{x} /$ $\mathrm{NO}_{x}$ interaction. Nature 1985;315:207-10. doi:10.1038/315207a0

28 United Nations. The Vienna Convention for the Protection of the Ozone Layer. https://ozone.unep. org/treaties/vienna-convention

29 United Nations. The Montreal Protocol on Substances that Deplete the Ozone Layer. https://ozone.unep. org/treaties/montreal-protocol

30 United Nations. The Montreal Protocol evolves to fight climate change. https://www.unido. org/our-focus-safeguarding-environmentimplementation-multilateral-environmentalagreements-montreal-protocol/montreal-protocolevolves-fight-climate-change

31 Rajan D, Mathurapote N, Putthasri W, et al. Institutionalising participatory health governance: lessons from nine years of the National Health Assembly model in Thailand. BMJ Glob Health 2019;4(Suppl 7):e001769. doi:10.1136/ bmjgh-2019-001769

32 Callahan EA, Hollander M, McGhie DV, Simpson S, Birnbaum J, Vinluan MH. Voices for Healthy Kids: a multisectoral collaboration to accelerate policy changes that promote healthy weight for all children and adolescents in the United States. BMJ 2018;363:k4763. doi:10.1136/bmj.k4763

33 Perez Arredondo AM, Yasobant S, Bruchhausen W. Bender K, Falkenberg T. Intersectoral collaboration shaping One Health in the policy agenda: a comparative analysis of Ghana and India. One Health 2021;13:100272. doi:10.1016/j. onehlt.2021.100272

34 Wamsler C, Wickenberg B, Hanson $\mathrm{H}$, et al. Environmental and climate policy integration: Targeted strategies for overcoming barriers to naturebased solutions and climate change adaptation. J Clean Prod 2020;247:119154. doi:10.1016/j. jclepro.2019.119154

35 Aartsen M, Koop S, Hegger D, et al. Connecting water science and policy in India: lessons from a systematic water governance assessment in the city of Ahmedabad. Reg Environ Change 2018;18:244557. doi:10.1007/s10113-018-1363-1

36 Van der Vliet N, Den Broeder L, Staatsen B, et al. INHERIT: success factors, barriers and future of intersectoral cooperation: a qualitative evaluation of twelve INHERIT case studies. EuroHealthNet, 2019. https://inherit.eu/wp-content/uploads/2020/02/ D5.1-Success-Factors-Barriers-and-Future-ofIntersectoral-Cooperation.pdf

37 APEC Secretariat. Partnerships for the sustainable development of cities in the APEC region. 2018. www.citiesalliance.org/sites/default/files/12Full\%20Report\%20APEC\%20Partnership\%20 Sustainable\%20Development.pdf 
38 de Leeuw E. Engagement of sectors other than health in integrated health governance, policy, and action. Annu Rev Public Health 2017;38:329-49. doi:10.1146/annurev-publhealth-031816-044309

39 Ravikumar A, Larson AM, Myers R, et al. Intersectoral and multilevel coordination alone do not reduce deforestation and advance environmental justice: Why bold contestation works when collaboration fails. Environment and Planning C: Politics and Space 2018;36:1437-57. doi:10.1177/2399654418794025

40 Who is more powerful-States or corporations? The Conversation 2018. https://theconversation. com/who-is-more-powerful-states-orcorporations-99616

41 Oreskes N. Conway EM. Merchants of doubt: how a handful of scientists obscured the truth on issues from tobacco smoke to global warming. Bloomsbury Press, 2010:6.

42 Ottersen OP, Dasgupta J, Blouin C, et al. The political origins of health inequity: prospects for change. Lancet 2014:383:630-67. doi:10.1016/S0140 6736(13)62407-1

43 Molina M, Zaelke D. The Montreal protocol: triumph by treaty. 2017. www.unep.org/news-and-stories/ story/montreal-protocol-triumph-treaty
44 Doyle K. The Montreal protocol-an ozone layer success story to remember amid the gloom of COP26. ABC Weather, 7 Nov 2021. www.abc.net.au/ news/2021-11-08/montreal-protocol-climate-talkscfc-phase-out-filling-ozone-hole/100560702

45 Marteau TM, Chater N, Garnett EE. Changing behaviour for net zero 2050. BMJ 2021;375:n2293. doi:10.1136/bmi.n2293

46 Delaney T, Lawless A, Baum F, et al. Health in All Policies in South Australia: What has supported early implementation? Health Promot Int 2016;31:888-9836.

47 Scheele CE, Little I, Diderichsen F. Governing health equity in Scandinavian municipalities: The inter-sectorial challenge. Scand I Public Health 2018;46:57-67. doi:10.1177/1403494816685538

48 IAP. The health of women, children and adolescents is at the heart of transforming our world: empowering accountability report. 2021. iapewec.org/reports/ iap-2021-final-report

49 Setzer J, Higham C. Global trends in climate change litigation: 2021 snapshot. Grantham Research Institute on Climate Change and the Environment and Centre for Climate Change Economics and Policy, London School of Economics and Political Science, 2021.

50 United Nations Development Programme. A guide to carbon pricing and fossil fuel subsidy reform: a summary for policymakers. 2021. www.undp.org/ publications/guide-carbon-pricing-and-fossil-fuelsubsidy-reform

51 UN Human Rights Office of the High Commissioner Bachelet hails landmark recognition that having a healthy environment is a human right. 2021. www. ohchr.org/EN/NewsEvents/Pages/DisplayNews. aspx?News $\mid \mathrm{D}=27635$ \&Lang $\mid \mathrm{D}=\mathrm{E}$

52 Yong E. How public health took part in its own downfall. Atlantic 2021 Oct 23. www.theatlantic com/health/archive/2021/10/how-public-healthtook-part-its-own-downfall/620457/

53 Dasandi N, Graham H, Lampard P, Jankin Mikhaylov S. Engagement with health in national climate change commitments under the Paris Agreement: a global mixed-methods analysis of the nationally determined contributions. Lancet Planet Health 2021;5:e93-101. doi:10.1016/S25425196(20)30302-8

54 United Nations. High-level political forum on sustainable development. https:// sustainabledevelopment.un.org/hlpf

Cite this as: $B M / 2022 ; 376: \mathrm{e} 068124$ http://dx.doi.org/10.1136/bmj-2021-068124 